\title{
O DESENHO, UMA DISCIPLINA DE PREPARAÇÃO PARA UMA PROFISSÃO
}

\author{
DRAWING, A DISCIPLINE PREPARING FOR A PROFESSION
}

\author{
Alexandra Rodrigues ${ }^{1, *}$ \\ José Manuel Matos ${ }^{1}$
}

\begin{abstract}
RESUMO: Pretende-se averiguar a importância que o ensino do desenho assume na educação técnico-profissional. Em primeiro lugar, buscaremos a evolução das intenções legislativas sobre o ensino dessa disciplina e o modo como seu âmbito foi sendo alterado. Em segundo lugar, analisa-se um manual prestigiado do princípio do século XX, que condensa o saber escolar sobre desenho, tal como era entendido nessa época.
\end{abstract}

Palavras-chave: Desenho. Desenvolvimento curricular. Ensino técnico profissional.

\begin{abstract}
The article intends to ascertain the importance of teaching drawing in technical and professional education. First, we will look for the evolution of the legislative intentions on teaching this discipline and the way its scope has been changed. Second, we analyse a prestigious manual from the beginning of the 20th century, that which condenses school knowledge about drawing, as it was understood at that time.
\end{abstract}

Keywords: Drawing. Curriculum development. Technical education.

1. Universidade Nova de Lisboa - Faculdade de Ciências e Tecnologia - Centro Interdisciplinar de Ciências Sociais - Lisboa, Portugal

*Autor correspondente: alexsofiarod@gmail.com

Número temático organizado por Wagner Rodrigues Valente 


\section{Introdução}

Com este texto, pretendemos contribuir para o conhecimento do saber escolar associado à disciplina de desenho nos cursos profissionais e, por esse meio, averiguar a importância que o ensino do desenho assume para a formação de técnicos intermédios, especialmente no que concerne ao ensino técnico-profissional.

Este objetivo será atingido usando um duplo olhar. Em primeiro lugar, recorrendo ao quadro legislativo, destacaremos as intenções governamentais para a introdução do desenho ao longo das sucessivas transformações do ensino técnico-profissional em Portugal, referindo as polémicas ocorridas durante o século XIX. Esse tipo de ensino inicia-se na segunda metade do século XVIII, através da criação de escolas próprias, e, mais tarde, já durante a segunda metade do século XIX, de disciplinas específicas criadas em escolas profissionais. Terminaremos esta revisão em 1910, com o eclodir da República. Conheceremos, assim, as normas (JULIA, 1995) associadas à disciplina.

Em segundo lugar, procurando identificar o saber escolar objetivado (BARBIER, 1996), detalharemos a abordagem didática do primeiro compêndio escolar aprovado para o ensino da disciplina de desenho linear, usado nos cursos técnico-profissionais portugueses do início do século XX.

Poderíamos igualmente afirmar que este trabalho se enquadra no âmbito dos estudos curriculares (GIMENO SACRISTÁN, 2000), versando sobre dois domínios associados ao desenho: o currículo prescrito desenvolvido pela administração central e que se manifesta essencialmente através da legislação; e o currículo apresentado aos professores através dos mediadores do ensino-aprendizagem, entre os quais se encontram os manuais escolares.

Em Portugal, a introdução do desenho já foi estudada por Lígia Penim (2008), que o discutiu em paralelo com a disciplina de português, e Clara Brito (2014), que explorou a sua dualidade em termos de representação artística e de representação do real. É, no entanto, ainda uma área de investigação pouco explorada. De facto, como Penim refere, "são escassos os trabalhos dedicados à história das disciplinas escolares no ensino técnico" (2008, p. 19), situação que não se alterou nos últimos doze anos. No Brasil, Marcos Guimarães (2017) estudou as finalidades do ensino de desenho na educação básica e foram efetuados dois trabalhos por Cristina Oliveira e Eliene Lima (2020) e Eliene Lima e Janice Lando (2020) abordando o ensino do desenho nos primeiros anos escolares. No que se refere ao ensino técnico, o trabalho de Elmha Moura (2016) contem uma reflexão sobre a importância do desenho na formação profissional.

\section{Metodologia}

Os factos históricos são construções do historiador a partir das suas questões de investigação, que, ao problematizar e levantar hipóteses sobre as evidências do passado encontradas no presente, transforma-as em fontes para a investigação, com vista à construção de factos históricos que respondem às questões previamente formuladas.

As dimensões retóricas e narrativas da história requerem que o conhecimento histórico seja construído pelas evidências da pesquisa a partir de provas que provêm de fontes escritas ou de entrevistas orais (CHARTIER, 2007). A constituição de fontes é uma das tarefas mais difíceis na metodologia histórica, pois carece da reunião de documentos detentores de informações que sejam pertinentes para o objeto estudado, constituindo um universo abrangente: livros didáticos, diários de classe, exames, provas, livros de atas, fichas de alunos e toda a documentação que faça parte dos arquivos das escolas e dos arquivos pessoais de alunos e professores (VALENTE, 2007). No processo de investigação histórica, o primeiro passo é o da seleção e do 
planeamento do estudo, definindo o esquema conceptual e o referencial teórico do objeto a estudar (MELO, 2010). O passo seguinte é o estabelecimento de uma hipótese de trabalho. Para este artigo, as fontes utilizadas foram catalogadas e sua interpretação teve em mente o espírito crítico que permitiu questionar as fontes documentais utilizadas, possibilitando a construção do conhecimento histórico (RODRIGUEZ, 2010).

Acompanhando os dois propósitos deste texto, na primeira fase do trabalho, os autores analisaram a legislação sobre as sucessivas reformas legislativas no ensino técnico-profissional, entre 1836 e 1910. Esses dados foram cruzados com outras fontes documentais, que se assumem como fidedignas na história da educação matemática em Portugal, em particular sobre o ensino do desenho no sistema de ensino público português, tendo como base um trabalho anterior dos autores deste artigo (RODRIGUES, 2014b).

Para conhecermos como o saber escolar se consolidou, segundo propósito deste texto, selecionámos o Compêndio de Desenho, de José Miguel de Abreu e António Teixeira Machado, aprovado como livro único a partir de 1900. Para o estudar, foi adotada uma classificação geral de itens: teoria e prática, proposta por Isabel Sousa (2012) para analisar manuais do ensino técnico.

\section{Opções Governamentais sobre o Ensino do Desenho}

A primeira medida visando introduzir um tipo de ensino público focado numa formação técnica em Portugal foi tomada pelo Marquês de Pombal, que criou a Aula do Comércio, cujos estatutos datam de 19 de abril de 1759 (RODRIGUES, 2015). Também na área da formação artística, foram criadas diversas escolas: a Aula de Desenho e Fábrica de Estuques e a Aula Oficial de Gravura Artística, em Lisboa, em 1768, acompanhadas, em 1779, pela Aula Pública de Debuxo e Desenho, no Porto (FRANCO et al., 2004). Essas escolas foram as precursoras das atuais Faculdades de Belas-Artes de Lisboa e do Porto. O desenho também estava presente como disciplina em academias militares, por exemplo na Academia Real de Fortificação, Artilharia e Desenho, fundada em 1790.

É, no entanto, a partir de meados de 1830 que a convicção de que a formação profissional deveria ser entregue a escolas especializadas, que permitissem ao país ultrapassar o seu atraso em relação a outros países europeus, começa a tornar-se realidade (RODRIGUES, 2015). Essa preocupação com uma formação profissional vai também estar presente nos decretos fundadores da Escola Politécnica, em Lisboa, e da Academia Politécnica do Porto (GOMES, 1996), na década de 1830. Também a reforma de Costa Cabral para o ensino primário (PORTUGAL, 1844) incorpora um $2^{\circ}$ grau, dotado de uma formação profissionalizante, no qual uma das disciplinas a lecionar seria desenho linear, num elenco curricular em que encontramos a gramática, a geografia, a história, a religião, a aritmética e a geometria (com aplicações à indústria) e a escrituração (MATOS; RODRIGUES; CANDEIAS, 2019).

Durante a segunda metade do século XIX, num contexto de crescimento económico apoiado por políticas públicas desenvolvimentistas lideradas por Fontes Pereira de Melo (o fontismo), concretizou-se um plano de escolas públicas vocacionadas para a formação profissional, contemplando as necessidades do país nas áreas da indústria, da agricultura e do comércio (BRITO, 2014; RODRIGUES, 2014). Analisando as propostas legislativas para a formação profissionalizante, verificamos que, para além de ler e escrever, seriam adicionados conhecimentos aplicados à vida profissional, através de disciplinas como desenho linear, geometria prática, noções de física, química, higiene e religião.

No processo de organização do sistema público de ensino em Portugal, o grande argumento para validar a inclusão do desenho como matéria de ensino foi o facto de este ser considerado um saber útil para a formação profissional de numerosos quadros, quer artísticos, na vertente das artes e ofícios, quer sobretudo técnicos (BRITO, 2014, p. 28). 
Em finais de 1852, Fontes Pereira de Melo regulamenta o ensino industrial não superior em Lisboa e no Porto, segmentando-o em três graus: elementar, secundário e complementar (PORTUGAL, 1852). O desenho fará parte do currículo nos três graus, a saber: no ensino elementar, será ministrada a cadeira de desenho linear e de ornatos industriais; e, nos ensinos secundário e complementar, a cadeira de desenho de modelos e máquinas ( $1^{\text {a }}$ e $2^{\text {a }}$ partes). A importância do ensino do desenho é reforçada com a criação, em 1856, de uma escola de ensino primário e princípios de geometria e desenho, destinada à aprendizagem dos artífices e aprendizes dos diversos ofícios, localizada em Lisboa (PORTUGAL, 1856).

Em 1864, o ministro das Obras Públicas, João Crisóstomo de Abreu e Sousa, regulamenta o currículo das escolas industriais existentes (PORTUGAL, 1864), no qual o desenho geométrico integra o elenco curricular do $1^{\circ}$ grau e o desenho linear e o desenho arquitetónico e ornatos, o do $2^{\circ}$ grau. O ministro pretende, ainda, criar escolas industriais em Guimarães, Covilhã e Portalegre, com cursos apropriados às indústrias dominantes naquelas localidades. No entanto, ao longo do século XIX, cada novo decreto dá a entender que o momento da sua publicação marca a inauguração do ensino técnico em Portugal (PENIM, 2008), uma vez que as dificuldades económicas do Estado para o financiamento das escolas de desenho industrial e das escolas industriais não permitem pôr em prática o que é regulamentado pela sucessiva legislação.

Por exemplo, o decreto de 1864 sistematiza o currículo a implementar dentro de um projeto nacional, criando vários níveis de aprendizagem. A partir dessa data, pressupor-se-ia uma iniciativa subsequente de criação de escolas. Contudo, depois de um primeiro impulso na criação das escolas de Lisboa e do Porto, o alargamento da rede escolar não se concretiza.

Se não fossem as dificuldades do tesouro público com que atualmente temos que lutar, um tal influxo nos instigaria ainda a ampliar aquele ensino, estabelecendo escolas profissionais elementares nos principais centros industriais do país, onde se ministrasse a conveniente instrução teórica e pratica para o aperfeiçoamento das nossas indústrias, artes e ofícios, dando-lhe a direção mais adaptada às diversas especialidades locais (PORTUGAL, 1869, p. 865).

As complexidades de generalização das reformas curriculares no ensino técnico prendem-se com a dificuldade de conciliar um currículo nacional com a adequação do mesmo às necessidades económicas locais (PENIM, 2008). A diversidade de cursos e escolas e o desenvolvimento industrial diversificado são obstáculos à regulação do Estado no que concerne aos programas do ensino técnico-profissional. A essa diversidade, acresce ainda a heterogeneidade das classes, o que torna muito difícil formar grupos homogéneos de alunos.

\section{Polémica sobre as Finalidades do Ensino do Desenho}

No final de 1875, o governo nomeia uma comissão constituída por catorze pessoas, presidida pelo Marquês de Sousa Holstein (1838-1878) e secretariada por Luciano Cordeiro (1844-1900), com o objetivo de propor uma reforma do ensino artístico e a organização do serviço dos museus, monumentos históricos e arqueologia. Os trabalhos da comissão são sumariados no relatório apresentado no início de 1876 (HOLSTEIN, 1875), no qual a comissão propõe manter as escolas superiores em Lisboa e no Porto e criar, em locais populosos de diferentes pontos do país, escolas de desenho destinadas à formação de operários. A comissão também sugere locais onde existam indústrias com tendência a desenvolver-se, por exemplo, cerâmica nas Caldas da Rainha, ourivesaria em Guimarães, rendas em Peniche e na Madeira. 
O relatório propõe, ainda, a criação de ensino de desenho pensado especificamente para o sexo feminino, "aulas para mulheres" (HOLSTEIN, 1875, p. 23), dirigido às que praticam os seguintes ofícios: pintura de leques, pintura de louças, desenho de vinhetas para livros ilustrados etc.

Além disso, o relatório tem secções destinadas à organização dos museus e das suas coleções, aos monumentos históricos e à arqueologia. É clara a importância para o desenvolvimento económico e industrial do país que a comissão atribui ao ensino do desenho,

[...] pois é certo que há no nosso país inúmeras profissões que muito poderiam desenvolver-se, e trazer indiretamente o aumento da riqueza pública, se porventura se tratasse com alguma seriedade de pôr ao seu alcance os recursos que necessitam. São factos conhecidos de todos o desenvolvimento que tem tomado a exportação da cantaria lavrada para o Brasil, a procura que nos mercados estrangeiros têm alguns dos nossos artefactos de ourivesaria e de cerâmica, o emprego que torna a ter o azulejo nas construções modernas, o favor com que são comprados objetos de mobília antigos, entalhados e marchetados e o grande número de oficinas que se têm aberto em Lisboa, para reparar ou mesmo imitar (HOLSTEIN, 1875, p. 14).

$\mathrm{Na}$ época, esse relatório foi criticado por Joaquim de Vasconcelos (1849-1936), uma das figuras nacionais que, na segunda metade do século XIX, argumentam sobre as finalidades do ensino do desenho. Na sua análise (VASCONCELLOS, 1877), o crítico de arte defendeu o ensino do desenho como conhecimento, arte e símbolo da formação e especialização dos setores industriais e artístico (BRITO, 2014). Acrescenta que a reforma proposta continuava a basear-se numa conceção errada das prioridades, uma vez que, do ponto de vista desse autor, não sugeria uma reforma do ensino do desenho e o proposto para as escolas de aplicação era insuficiente, estabelecendo uma falsa relação entre a arte e a indústria.

Contudo, será na década de 1880 e sempre sob a tutela do Ministério das Obras Públicas que se expandirá o ensino profissional ao resto do país (RODRIGUES, 2014). Com a Reforma do Ensino Técnico, levada a cabo por António Augusto de Aguiar (PORTUGAL, 1884), passa a ser visível a relação entre o ensino e a sua aplicação à indústria, demarcando o desenho industrial do desenho artístico, cujo ensino era ministrado nas Academias de Belas-Artes. Agora, as cadeiras de desenho assumem-se como centrais no ensino industrial, podendo ler-se no prólogo do Regulamento Geral das Escolas Industriais e Escolas de Desenho Industrial:

[...] as cadeiras ou escolas de desenho, multiplicadas com o tempo, ir-se-ão constituindo gradualmente em escolas industriais, nos lugares e pela forma que as circunstâncias o aconselharem; e a rede destas escolas terá como centros os dois museus industriais e comerciais de Lisboa e Porto (PORTUGAL, 1884, p. 127).

O ensino do desenho será dividido em dois graus: um primeiro, designado por elementar ou geral e destinado às crianças menores de 12 anos, a ministrar antes da entrada no mercado de trabalho; e um segundo, industrial ou especial, destinado à formação de adultos, aprendizes ou mestres das várias indústrias e ofícios. Em ambos os níveis de ensino, é referido na legislação que deverá aplicar-se o método estimatográfico.

O ensino industrial do desenho é organizado em três ramos: ornamental, arquitetural e mecânico, com a duração de dois anos. No ramo ornamental, privilegia-se o ensino de desenho geométrico; desenho de ornato; perspetiva e aguadas; e modelação. No ramo arquitetural, estuda-se desenho geométrico; perspetiva e aguadas; estereotomia e corte de madeiras; desenho arquitetónico e ornato arquitetural; desenho topográfico; e elaboração de cortes, plantas e perfis. No ramo mecânico, são estudados desenho 
geométrico; perspetiva e aguadas; desenho à vista de máquinas; e elaboração de cortes. Essa organização por ramos revela a importância do ensino do desenho na formação industrial e da necessidade de especialização da formação consoante o ramo de aprendizagem.

São então criadas escolas industriais e de desenho industrial nos locais do país onde existiam grandes centros de produção. A primeira será na Covilhã e terá como objetivo um ensino eminentemente prático, adequado às necessidades das indústrias locais, vocacionadas para a tinturaria. $\mathrm{O}$ mesmo decreto cria mais oito escolas de desenho industrial (três em Lisboa, três no Porto, uma nas Caldas da Rainha e uma em Coimbra). Essas escolas tinham como objetivo ministrar o ensino do desenho exclusivamente industrial e com aplicação às indústrias que predominavam nessas localidades (BRITO, 2014). O programa das cadeiras de desenho publicado no regulamento supracitado recomenda que tais cadeiras assumam uma vertente iminentemente prática. Essa formação será monitorizada pelos inspetores, uma vez que:

[....] o método e os processos de ensino utilizados pelos professores serão cuidadosamente estudados nos seus resultados pelos inspetores, que, nos seus relatórios, apresentarão os alvitres que entenderem oportunos, instruindo por todas as formas as instâncias superiores (PORTUGAL, 1884, p. 127).

Clarificando essa segmentação do ensino do desenho, três anos depois, em 1887, com Emídio Navarro nas Obras Públicas, é aprovado o Plano de Organização do Ensino Industrial e Comercial (PORTUGAL, 1887), que organiza o ensino do desenho em três cadeiras diferentes: desenho linear, de figura, ornato, paisagem do natural e modelação; desenho de máquinas, construção de peças elementares e respetiva tecnologia; e desenho arquitetónico e topográfico, cortes e plantas de minas.

Até junho de 1888, foram criadas cinco escolas industriais e dezassete de desenho industrial, em muitos casos a pedido das próprias localidades. O plano de estudos é fixado para cada um dos ramos do curso, deixando-se liberdade aos professores para a organização dos programas, que seriam posteriormente analisados por inspetores e alvo de relatório a apresentar posteriormente (BRITO, 2014). O Regulamento das Escolas Industriais e de Desenho Industrial, publicado a 24 de fevereiro de 1988 (PORTUGAL, 1888) e assinado por Emídio Navarro, distingue os programas das disciplinas de desenho a lecionar nas diferentes escolas.

Iniciando-se com a estadia de João Franco no Ministério das Obras Públicas, em 1891, e continuando com os ministros que o sucederam, proceder-se-á a uma reorganização global do ensino profissional (RODRIGUES, 2015). Acreditava-se, então, no papel do sistema educativo na formação de um povo e na aposta de instruir a classe operária para fomentar o progresso social e económico do país. $\mathrm{O}$ ensino industrial e comercial é então segmentado em dois sistemas: as escolas industriais, disseminadas pelo país e destinadas a um ensino inicial e profissional de aprendizes - por sua vez subdivididas em completas, incompletas e elementares -, e os institutos industriais e comerciais, estabelecimentos de ensino médio localizados em Lisboa e no Porto (PORTUGAL, 1891). Essa reorganização engloba todo o sistema de ensino industrial e comercial, incluindo os institutos, os museus industriais e comerciais e as escolas industriais, pondo fim aos cursos elementares nos dois institutos. Nos cursos industriais, as cadeiras de desenho abrangem a aplicação à indústria, à arquitetura e à construção de máquinas, não fazendo parte do plano de estudos dos cursos comerciais.

Em 1897, há novas reorganização e regulamentação das escolas industriais e de desenho industrial (PORTUGAL, 1897), que pretende condensar num único diploma toda a legislação dispersa a respeito das escolas industriais, tentando imprimir à organização dos cursos uma orientação mais clara. 


\section{Compêndios de Desenho do Período em Estudo}

A objetivação de saberes escolares em livros escolares (BARBIER, 1996) é um processo complexo, que assume especial dificuldade nos saberes propostos para o ensino do desenho nos cursos técnico-profissionais. Entre 1836, data da criação do sistema público de ensino em Portugal, e 1895, ano em que, pela primeira vez, é decretado o livro único para o ensino liceal (Reforma, de Jaime Moniz), decorre um período durante o qual, devido a todo o tipo de carências, o governo incentiva, mediante pagamento de serviços, o aparecimento de autores e obras escolares (BRITO, 2014). As primeiras edições portuguesas de manuais escolares para o ensino do desenho no sistema de ensino secundário público provêm da iniciativa autodidata de professores que, usando a sua experiência docente, assumem-se como autores que divulgam, dessa forma, os seus conhecimentos, obtidos por compilação, tradução ou adaptação de outros textos e adquiridos ao longo da sua experiência profissional (BRITO, 2014). Em parte devido à inexistência de programas (como foi o caso da disciplina de desenho), foram os autores-professores os responsáveis pela organização das matérias e dos métodos de ensino, os quais eles condensaram em compêndios em que estavam subjacentes as suas conceções didático-pedagógicas adquiridas em contexto de prática docente (BRITO, 2014; SOUSA, 2012).

De acordo com Célia Leme da Silva (2019), é notório o papel ativo da escola na compreensão de que os saberes escolares não são estáticos, modificando-se ao longo do tempo e do espaço como respostas às diferentes solicitações da sociedade, especialmente no que se refere à preparação profissional de técnicos intermédios. Dessa forma, assume importância pedagógica significativa o facto de que os primeiros manuais escolares de desenho usados para o ensino da disciplina em Portugal tinham por base a experiência pedagógica dos professores da disciplina, que se apresentam como peritos na temática a desenvolver no âmbito das propostas pedagógicas que apresentam (BRITO, 2014; SILVA, 2019). Assim, o manual escolar pode ser entendido como uma fonte para a análise das opções metodológicas e pedagógicas dos autores que lecionavam a disciplina e, paralelamente, como um meio privilegiado de percecionar quais os conteúdos lecionados a um determinado nível de ensino, o que Jean-Marie Barbier (1996) designa de saber objetivado.

Para o ensino do desenho nos liceus, o primeiro autor de manuais escolares que se conheceu foi Teodoro da Mota (1833-1894), professor da família real, de liceus e da Escola Normal Primária Feminina, que publicou sucessivas edições do seu Compêndio de Desenho Linear entre 1868 e 1892, distribuído em três anos ( $1^{\circ}, 2^{\circ}$ e $3^{\circ}$ ano dos liceus), com as imagens e textos organizados separadamente em atlas e livros de texto (BRITO, 2014; PENIM, 2012).

Os seus compêndios, comportando conteúdos relativos ao desenho geométrico e ao desenho à vista, de acordo com o conceito e o método do Desenho Linear, eram constituídos por um livro de texto exclusivamente destinado aos enunciados dos exercícios de geometria e respetivas definições, e aquilo que designará por "Atlas". Este trata-se de um álbum encadernado e geralmente de dimensões maiores que o livro de texto, constituído por desenhos do autor ilustrando os traçados geométricos, com uma numeração em estreita correspondência com o livro de texto, e desenhos de ornamentos e elementos da arquitetura que serviriam como modelo a um desenho aplicado (BRITO, 2014, p. 41-42).

Contudo, de acordo com Lígia Penim (2008), apesar de Joaquim Vasconcelos considerar de qualidade o compêndio de Teodoro da Mota, o livro tinha características de um manual oitocentista, necessitando de atualização no final do século XIX, por forma a dar resposta ao regime de classe e à 
distribuição do conhecimento por idades, como previsto na reforma liceal de 1894-1895. A preocupação com a idade do aluno reflete-se pela primeira vez no Compêndio de Desenho Linear Elementar, de José Miguel Abreu (1850-1921), professor do Instituto Industrial e Comercial do Porto, professor interino do liceu central da mesma cidade e antigo professor proprietário da cadeira de desenho anexa à Faculdade de Matemática da Universidade de Coimbra. O texto é destinado aos liceus e publicado desde antes de 1879 até 1895 , continuando outros dos livros desse autor para o ensino de desenho a serem publicados até ao final da década de 1900 .

O foco deste artigo é, no entanto, não o ensino nos liceus, mas o ensino técnico-profissional, no qual era usado o método estimográfico de Grandauer, como vimos, divulgado em Portugal por Joaquim de Vasconcelos no seu texto para a Reforma do Ensino do Desenho (1877). O método é introduzido no programa de desenho das escolas industriais e de desenho industrial, em 1886, e no programa da disciplina de desenho do ensino liceal proposto pela Reforma, de Jaime Moniz, em 1895. Esse método consistia na criação de uma rede estimográfica pelo aluno, que serviria de base para a elaboração do desenho (LOBO, 1998) e esteve na base da organização dos compêndios de José Miguel de Abreu e António Teixeira Machado, aprovados como livro único a partir de 1900. Estudaremos esses compêndios detalhadamente nesta secção do artigo. Não obstante a facilidade de ensino, o método foi fortemente criticado no final do século XIX. Segundo as críticas, os alunos apenas se limitavam aos espaços quadriculados das folhas e assim não aprendiam a desenhar por si próprios. Embora o método recorra a um excesso de coerção, importa igualmente sublinhar que traduz já uma verdadeira sequencialização das aprendizagens de desenho (PENIM, 2011).

O ensino do desenho nas escolas profissionais recorre frequentemente a modelos. No Congresso Pedagógico Hispano-Português-Americano de 1892, José Miguel de Abreu refere o caráter profissionalizante do ensino industrial. Esse autor descreve detalhadamente o espólio educativo existente nas oficinas, que diz terem excelente material para o ensino do desenho industrial, existindo, no Instituto do Porto, perto de oitocentos modelos de gesso para o estudo do desenho ornamental e de figura, coleções de órgãos de máquinas, de pinturas e de esculturas (PENIM, 2008). Também o inventário dos materiais didáticos para a disciplina de desenho na Escola Secundária Soares dos Reis, desde a década de 1880 até a de 1940, levado a cabo por Maria Natália Lobo, refere a existência de 127 obras didáticas, coleções de estampas e modelos tridimensionais (BRITO, 2014). Esse apreço em torno das condições materiais das escolas técnicas pressupõe a existência de uma grande valorização das aulas práticas em prol da teorização existente nos manuais escolares, não sendo esse o recurso educativo privilegiado (BRITO, 2014; PENIM, 2008).

Como vimos, no final do século XIX, orientada por Joaquim Vasconcelos, a discussão centra-se na função pedagógica do desenho e na sua importância para o desenvolvimento económico do país, num processo de industrialização, que afirma a sua importância em todos os níveis de ensino comparativamente ao ensino da língua portuguesa. Esse discurso tem continuidade durante a Primeira República e está presente nas primeiras reformas do Estado Novo, até perto de 1930 (PENIM, 2008).

\section{O Compêndio de Desenho de Teixeira Machado e José Abreu}

Em termos legislativos, ao longo da segunda metade do século XIX, houve uma tentativa de uniformização na utilização dos manuais escolares aprovados para efeitos de aprendizagem no ensino secundário. De facto, em 1860, o Conselho Geral de Instrução Pública afirma a necessidade de uniformizar o ensino, assegurando o acesso a compêndios que manifestamente não tivessem erros 
científicos ou de linguagem, revelando a preocupação com a uniformização do ensino com meios didáticos que fossem iguais para todos (PORTUGAL, 1860). A partir da década de 1880, a lista de manuais propostos pelos conselhos dos liceus passa a ser sancionada pelo Conselho Geral de Instrução Pública e, nos anos seguintes, novas portarias fixam a lista dos livros aprovados para esse ano (PENIM, 2008). De acordo com a autora em questão, após a reforma dos liceus, em setembro de 1895, é publicada uma primeira lista de livros aprovados para o ensino liceal e o livro para a disciplina de desenho fica entregue a José Miguel de Abreu e António Luiz de Teixeira Machado, esse último, coronel de infantaria, professor da Escola Maria Pia e antigo professor do Liceu de Lisboa e do Porto. Será o Compêndio de Desenho desses dois autores (MACHADO; ABREU, 1902) o manual que estudaremos nesta secção.

Para o ensino técnico, essa lista de manuais aprovados só irá acontecer passados trinta anos, inicialmente para o ensino comercial e só posteriormente para o ensino industrial (PENIM, 2008). $\mathrm{Na}$ ausência de livros específicos para o ensino técnico, os compêndios de desenho procuravam ir de encontro a um público diversificado, endereçando-se aos alunos dos liceus e das escolas técnicas em simultâneo. De facto, podemos ler na capa do Compêndio de Desenho, de Teixeira Machado e José Abreu, "Obra aprovada por Decreto de 16 de novembro de 1899, para servir ao ensino secundário em todos os Liceus, Escolas, Colégios e Institutos de instrução secundária, durante os anos letivos de 18991900, 1900-1901, 1901-1902” (1902). De acordo com Penim (2008), esse manual conjugou uma série de mecanismos de legitimação, justificando a sua pertinência pela utilização do método estimográfico de Grandauer, e contou com o parecer favorável de Joaquim Vasconcelos (respeitado crítico de arte). A relevância desse compêndio reside, entre outros aspetos, na capacidade de transmitir claramente os objetivos do ensino, de organizar os saberes, de enunciar experiências de vida comuns e de permitir um ensino mais generalizado, adequado à faixa etária e à disposição de uma escola massificada. Em termos gerais, o compêndio de Teixeira Machado e Abreu assume-se como um manual escolar de referência, cumprindo as especificidades para a elaboração desse tipo de material e sua missão pedagógica para a educação (PEREIRA, 2010). Tomando em conta esse reconhecimento institucional, optámos por estudar o saber objetivado sobre o ensino do desenho dos inícios do século XX, tal como ficou condensado nos manuais de Teixeira Machado e José Abreu.

Uma primeira análise da edição de 1902 do compêndio (MACHADO; ABREU, 1902) permitenos verificar que as primeiras páginas são dedicadas a referir outras obras dos autores e a agradecer aos desenhadores e gravadores em metal e madeira que colaboraram na obra. Entre as páginas 5 e 13, é republicado o programa de desenho para a classe a que o livro se destina e, após um prólogo de onze páginas, encontram-se vinte capítulos nos quais se encontra organizada a matéria do programa da disciplina.

No prólogo, é patente a conceção dos autores sobre o ensino de desenho, podendo ler-se, logo no início:

O ensino do desenho elementar não tem por fim único, nem mesmo principal, ministrar uma aptidão, que na vida prática é importantíssima, por ser o modo de exprimir ideias com universalidade, clareza, concisão e precisão, que a mais cuidada linguagem, falada ou escrita, está longe de possuir que a vantagem dos livros ilustrados prova exuberantemente (MACHADO; ABREU, 1902, p. 14).

Conseguimos também encontrar algumas conceções didático-pedagógicas dos autores, nomeadamente no que concerne ao rigor e à clareza necessários para o ensino da disciplina. Os autores fazem algumas considerações acerca das metodologias a adotar na aula relativamente ao ensino 
oral descritivo, ao desenho rigoroso, ao desenho à vista e à metodologia de ensino a adotar na aula, importada da Alemanha, tendo em conta a idade dos alunos.

Nas lições orais da $1^{\text {a }}$ classe, o professor, de vinte e cinco em vinte e cinco minutos, pouco mais ou menos, fará uma pausa de cerca de cinco minutos, passados os quais reatará a lição interrompida, tendo o cuidado em ordenar esta por forma a que a exposição feita em cada período, bem como em cada dia de aula, constituam um todo, que as interrupções não prejudiquem.

Para conservar tensa a atenção dos alunos, o começo de cada lição, ou período, será indicado com o vocativo Classe! pronunciado em voz suficientemente alta, clara e com intimativa. Pode ser acompanhado por uma pancada na mesa, ou na palma da mão com a força bastante para ser ouvida por toda a classe.

[...] As perguntas devem enunciar-se antes de ser indicado o aluno escolhido para responder; as respostas serão dadas por proposição completa.

O fim do período de atenção será indicado por um sinal do professor (MACHADO; ABREU, 1902, p. 17-18).

O livro termina com um conjunto de 56 estampas que seriam utilizadas como material auxiliar (exercícios de aplicação) do ensino da disciplina. Repare-se na exigência dos exercícios 45 e 46 (Estampa 19a), referentes ao desenho de ornatos num octógono regular.



Fonte: MACHADO; ABREU, 1902, s. p.

Figura 1. Estampa 19a. 
Para a análise dos capítulos do manual, foi adotada uma classificação geral de itens: teoria e prática, proposta por Isabel Sousa (2012) para manuais do ensino técnico. Esta autora considerou teoria qualquer elemento que consistisse na apresentação e na exploração de um conceito ou procedimento, incluindo aqui todos os exemplos de aplicação (textos introdutórios, definições e exemplos de aplicação de conceitos). Na classificação da prática foram incluídos todos os exercícios e tarefas cuja resolução não se encontra manual (distinguem-se os exercícios dos problemas, requerendo esses últimos mobilização de saberes para a interpretação da questão colocada, do que o faria uma operação para a sua resolução).

Embora o compêndio seja estruturado em vinte capítulos, esses encontram-se separados em itens numerados entre 1 e 222. Ao longo dos capítulos, encontramos itens em numeração romana, que remetem para a realização de um conjunto de 129 exercícios das estampas. Procedendo a uma análise quantitativa e sistematizada (MCCULLOCH, 2004), agrupámos os itens em quatro categorias: conceções teóricas, material necessário, técnicas de aplicação prática no desenho e exercícios de aplicação, explicitadas na Tabela 1 .

Tabela 1. Número de itens por categoria do Compêndio de Desenho de 1902.

\begin{tabular}{ccccc}
\hline Capítulos & Conceções teóricas & Material necessário & $\begin{array}{c}\text { Técnicas de } \\
\text { aplicação prática }\end{array}$ & $\begin{array}{c}\text { Exercícios } \\
\text { de aplicação }\end{array}$ \\
\hline Cap. I & 18 & - & 4 & - \\
Cap. II & 4 & 20 & 12 & - \\
Cap. III & 1 & - & 12 & 3 \\
Cap. IV & 6 & - & 2 & 6 \\
Cap. V & 11 & 2 & 3 & 4 \\
Cap. VI & 5 & 1 & 2 & 2 \\
Cap. VII & - & - & 2 & 8 \\
Cap. VIII & 7 & - & - & - \\
Cap. IX & 3 & - & - & 13 \\
Cap. X & 2 & - & 8 & 4 \\
Cap. XI & & - & 2 & 7 \\
Cap. XII & 6 & - & - & 9 \\
Cap. XIII & 4 & 1 & 6 & 12 \\
Cap. XIV & 7 & - & 20 & $(8)$ \\
Caps. XV-XVI-XVII* & $(15)$ & $(-)$ & $(1)$ & 3 \\
Cap. XVIII & 2 & - & - & 1 \\
Cap. XIX & 2 & - & - & 17 \\
Cap. XX & 26 & 1 & 2 & 4 \\
\hline
\end{tabular}

*Não foi possível classificar 5 itens e 15 exercícios dos capítulos XV a XVII, porque faltam as páginas 119 a 128 do compêndio que analisámos.

Como observamos na tabela, o manual tem uma distribuição pedagógica muito equilibrada em relação aos itens que categorizámos. Exceptuando o capítulo I, em que são apresentadas noções básicas das conceções teóricas a utilizar ao longo do texto, e o capítulo II, no qual há uma preocupação dos autores em enumerarem a maior parte do material necessário para a disciplina do desenho, a partir do capítulo III, após a exposição das conceções teóricas subjacentes e a explicação do material 
necessário, o compêndio apresenta exercícios práticos integrados à matéria lecionada. A apresentação de teoria é, pois, normalmente acompanhada de uma exploração técnica seguida de bastantes exercícios de aplicação.

No manual, a sequência de apresentação dos conteúdos teóricos é sempre seguida dos procedimentos práticos a adotar para a aplicação da prática. Por exemplo, no item 77 (capítulo IV) os autores definem linhas retas oblíquas. Essa definição é seguida pelo conceito linhas retas oblíquas no desenho (item 78) e pelo item 79, modo de traçar linhas oblíquas, que apresenta a técnica de aplicação prática. Há itens, embora em número reduzido, que pertencem simultaneamente a duas categorias, por exemplo, o item 86 , ângulos retos, define ângulo reto e esquadria, porém termina com a ilustração de como traçar um ângulo reto dobrando uma folha de papel (Fig. 2).

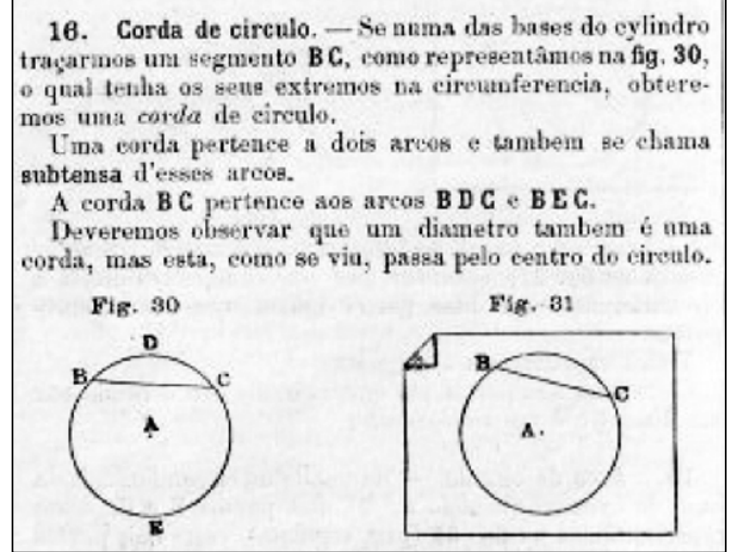

Fonte: MACHADO; ABREU, 1902, p. 61.

Figura 2. Representação de um ângulo reto.

Para melhor ilustrar exemplos práticos das categorias do manual, passamos a indicar um exemplo de cada uma delas. O item 16 ilustra a conceção teórica de corda de círculo, como podemos observar na Fig. 3.

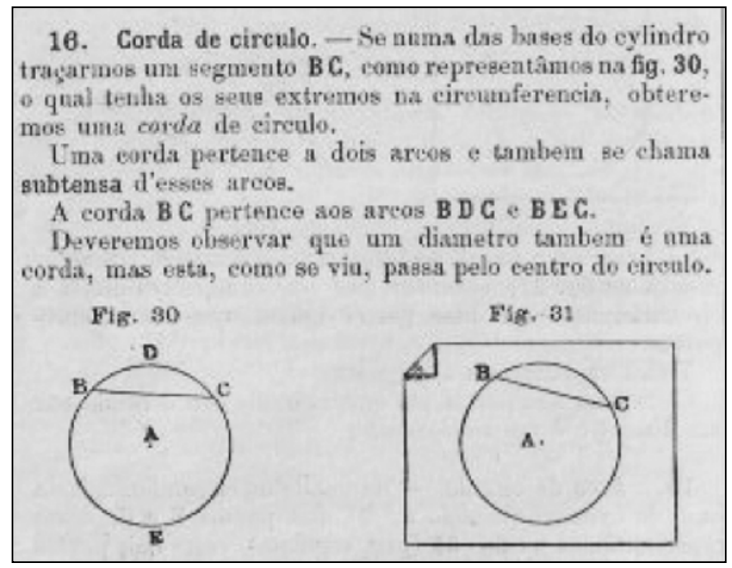

Fonte: MACHADO; ABREU, 1902, p. 34.

Figura 3. Corda de círculo.

Por serem materiais não usuais atualmente nas aulas contemporâneas, apresentamos os itens 34 e 35, que referem miolo de pão, camurça e goma elástica, atualmente designada por borracha, como pode ser observado na Fig. 4. 
34. Miolo de pão. Camurça. - Os traços do carvíio eliminam-se do papel, quasi inteiramente, por meio de wislo de pòo, que niko deve ser freseo, o que se amassa entrie os dedos pollegar e indieador, dando -se. Ihe uma förma arredondada. Foses tracos devem ser primeiramente sacudidos com um panno.

35 Gomma elastica. - A gomma elestica, ou borracho, serve para elinuinar do papel as linhas inuteis, depois de effeituada qualquer construegalo, ou as que se traçam erradamente,

E preciso que seja macia o homogenea a fim de fazer desapparecer os tragos eom fucilidade, sem damnificar o papel.

A gomma elastina meotra-8e no mereado preparada de varios modos a tendo yqulquer d'estals côre日: vermelha 1 , custumho-eвcuria ou cinzenta ${ }^{2}$.

Deve preferir-se a de côr cinzenta.

Ha tambem uma gomma elastica preta, conhecida pelo nome de borracka-piò, que, por ser plastica, é excellente para o desenho á vista, principalmente.

Fonte: MACHADO; ABREU, 1902, p. 40.

Figura 4. Materiais usados em Desenho.

Por fim, para ilustrar um item na categoria técnicas de aplicação prática, na figura seguinte (Fig. 5), mostramos o modo de traçar as linhas horizontais (item 76).

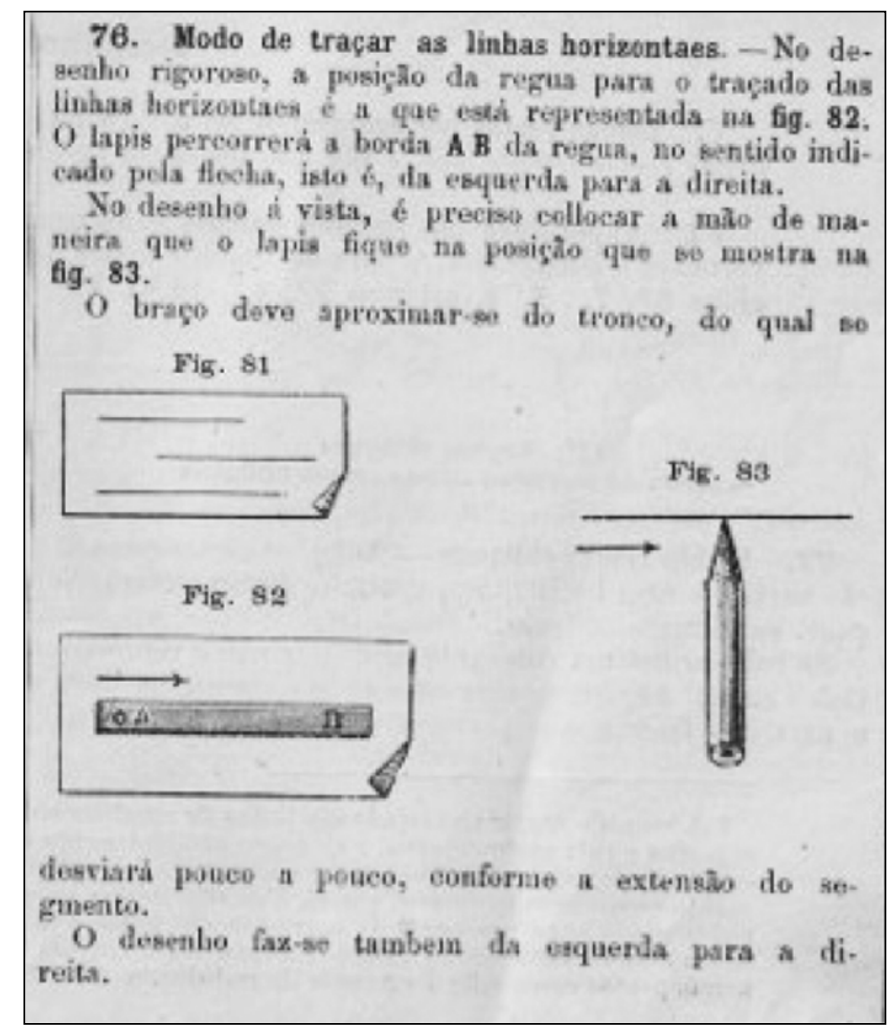

Fonte: MACHADO; ABREU, 1902, p. 55.

Figura 5 .Traçar linhas horizontais. 


\section{Considerações Finais}

Entre a criação de um sistema de ensino secundário público português, em 1836, e a implantação da República, em 1910, o ensino do desenho foi assumindo contornos importantes na formação de técnicos intermédios, especialmente no que respeita ao ensino industrial, tendo mesmo sido criadas escolas de desenho industrial específicas para a formação e a especialização de trabalhadores. Para o ensino de desenho nesses cursos, os docentes davam primazia às aulas práticas, recorrendo a materiais manipuláveis existentes nas oficinas onde decorria a formação. A primeira parte deste artigo procurou mostrar como, gradualmente, o âmbito da disciplina se foi alargando, expandindo-se de desenho como forma de expressão artística para desenho como ferramenta imprescindível na planificação industrial, de que é retrato a polémica da década de 1870 entre Holstein e Vasconcelos.

Paralelamente, foram sendo publicados alguns compêndios elaborados por professoresautores, que recorreram à sua experiência docente para propor sequências didáticas para o ensino do desenho. Para a segunda parte deste artigo, optámos por estudar o manual de Teixeira Machado e José Abreu, selecionado como livro único para o ensino liceal e também adotado no ensino profissional. O manual analisado é bastante equilibrado em todas as componentes, apresentando uma sequência didática adequada à idade dos formandos, com muitas tarefas de aplicação dos conceitos a aprender e indicações metodológicas para os diferentes procedimentos, inclusive no que respeita aos procedimentos a adotar pelo professor para lecionar. Pelas ilustrações bem conseguidas e enquadradas ao longo do manual, compreende-se que a sua aquisição não estivesse ao alcance dos alunos das escolas técnicas, o que dificultava o ensino da disciplina que recorresse ao manual escolar.

\section{Contribuições dos Autores}

Problematização e Conceitualização: Rodrigues A; Matos JM; Metodologia: Rodrigues A; Matos JM; Análise: Rodrigues A; Matos JM; Redação: Rodrigues A; Matos JM.

\section{REFERÊNCIAS}

BARBIER, J.-M. Introduction. In: BARBIER, J.-M. (ed.). Savoirs théoriques et savoirs d'action. Paris: PUF, 1996. p. 1-17.

BRITO, M. C. As disciplinas de desenho e de educação visual no sistema público de ensino em portugal, entre 1836 e 1986. Da alienação à imersão no real. 2014. Tese (Doutorado em Belas-Artes) - Faculdade de Belas-Artes, Universidade de Lisboa, Lisboa, 2014.

CHARTIER, R. La história o la lectura del tiempo. Barcelona: Gedisa, 2007.

FRANCO, M. L. et al. Ensino médio e ensino técnico no Brasil e em Portugal. Campinas: Editores Associados, 2004.

GIMENO SACRISTÁN, J. O currículo: uma reflexão sobre a prática. Porto Alegre: Artmed, 2000. 
GUIMARÃES, M. D. Por que ensinar desenho no curso primário? Um estudo sobre as suas finalidades (1829-1950). 2017. Tese (Doutorado em Ciências) - Escola de Filosofia, Letras e Ciências Humanas, Universidade Federal de São Paulo, Guarulhos, 2017.

HOLSTEIN, F. Observações sobre o actual estado do ensino das artes em Portugal, a organização dos museus e o serviço dos monumentos históricos e da arqueologia. Lisboa: Imprensa Nacional, 1875.

JULIA, D. La culture scolaire comme objet historique. Paedagogica Historica - International Journal of the History of Education, Philadelphia, v. 31, issue sup. 1, p. 353-382, 1995. https://doi.org/10.108 $0 / 00309230.1995 .11434853$

LIMA, E. B.; LANDO, J. C. A observação e o fazer para ensinar geometria, desenho e trabalhos manuais: a formação de professores e a pedagogia escolanovista. In: OLIVEIRA, M. C. A. J. D. et al. (eds.). A aritmética, a geometria e o desenho: a matemática nos primeiros anos escolares. São Paulo: Editora Livraria da Física, 2020. p. 159-177.

LOBO, M. N. M. M. O ensino das artes aplicadas (ourivesaria e talha) na Escola Faria Guimarães de 1884 a 1948. 1998. Dissertação (Mestrado em História de Arte) - Faculdade de Letras, Universidade do Porto, Porto, 1998.

GOMES, J. F. O ensino da pedagogia e da psicologia nas escolas normais primárias (1862-1974). Revista Portuguesa de Pedagogia, Coimbra, v. XXX, n. 2, p. 103-157, 1996.

MACHADO, A. L. T.; ABREU, J. M. Compêndio de desenho. Porto: Livraria Portuense, 1902.

MCCULLOCH, G. Documentary research: in education, history and the social sciences. Londres: Routledge Falmer, 2004.

MATOS, J. M.; RODRIGUES, A.; CANDEIAS, R. A formação profissional em escolas primárias e em escolas normais primárias portuguesas (1844-1926). Educação, Porto Alegre, v. 42, n. 2, p. 178-188, 2019. https://doi.org/10.15448/1981-2582.2019.2.33830

MELO, J. J. P. Fontes e métodos: sua importância na descoberta das heranças educacionais. In: COSTA, C. L. J. et al. (eds.). Fontes e métodos em história da educação. Dourados: UFGD, 2010. p. 13-34.

MOURA, E. C. M. O ensino de matemática em duas escolas profissionalizantes: Brasil e Portugal, no período de 1942 a 1978. 2016. Tese (Doutorado em Educação Matemática) - Instituto de Geociências e Ciências Exatas, Universidade Estadual Paulista Júlio de Mesquita Filho, Rio Claro, 2016.

OLIVEIRA, M. C. A. J. D.; LIMA, E. B. À mão livre ou com régua e compasso: saberes geométricos para o ensino primário em tempos da vaga pedagógica intuitiva. In: OLIVEIRA, M. C. A. J. D. et al. (eds.). A aritmética, a geometria e o desenho: a matemática nos primeiros anos escolares. São Paulo: Editora Livraria da Física, 2020. p. 135-157.

PENIM, L. A alma e o engenho do currículo: história das disciplinas de português e de desenho no ensino secundário do último quartel do século XIX a meados do século XX. 2008. Tese (Doutorado em Ciências da Educação) - Faculdade de Psicologia e de Ciências da Educação, Universidade de Lisboa, Lisboa, 2008. 
PENIM, L. Narrativa apanhada em pleno voo. A história do ensino do desenho. Trabalho apresentado no $3^{\circ}$ Colóquio Internacional sobre desenho: Educação, Cultura e Interatividade, 2011. [Salvador, BA].

PENIM, L. Histórias de autores menores. Lisboa: Repositório da Universidade de Lisboa, 2012. Mimeografado. Disponível em: http://hdl.handle.net/10451/7163. Acesso em: 4 nov. 2020.

PORTUGAL. Reforma da instrução pública. Colecção Oficial da Legislação Portuguesa 1844. Lisboa: Imprensa Nacional, 1844. p. 306-330.

PORTUGAL. Decreto. Colecção Oficial da Legislação Portuguesa 1852. Lisboa: Imprensa Nacional, 1852. p. 864-870.

PORTUGAL. Portaria. Colecção Oficial da Legislação Portuguesa 1856. Lisboa: Imprensa Nacional, 1856. p. 285.

PORTUGAL. Regulamento para a aprovação de livros para as escolas públicas. Colecção Oficial da Legislação Portuguesa 1860. Lisboa: Imprensa Nacional, 1860. p. 26-32.

PORTUGAL. Decreto regulando o ensino industrial em Lisboa, Porto, Guimarães, Covilhã e Portalegre. Colecção Oficial da Legislação Portuguesa 1864. Lisboa: Imprensa Nacional, 1864. p. 955-963.

PORTUGAL. Reforma do ensino industrial e comercial. Colecção Oficial da Legislação Portuguesa 1869. Lisboa: Imprensa Nacional, 1869. p. 865-888.

PORTUGAL. Regulamento geral das escolas industriais e escolas de desenho industrial. Colecção Oficial da Legislação Portuguesa 1884. Lisboa: Imprensa Nacional, 1884. p. 127-131.

PORTUGAL. Plano de organização do ensino industrial e comercial. Colecção Oficial da Legislação Portuguesa 1887. Lisboa: Imprensa Nacional, 1887. p. 952-962.

PORTUGAL. Regulamento das escolas industriais e de desenho industrial. Colecção Oficial da Legislação Portuguesa 1888. Lisboa: Imprensa Nacional, 1888. p. 83-93.

PORTUGAL. Decreto reorganizando o ensino industrial e comercial. Colecção Oficial da Legislação Portuguesa 1891. Lisboa: Imprensa Nacional, 1891. p. 595-617.

PORTUGAL. Decreto reorganizando as escolas industrias e de desenho industrial. Colecção Oficial da Legislação Portuguesa 1897. Lisboa: Imprensa Nacional, 1897. p. 455-467.

PEREIRA, A. B. Manuais escolares: estatuto e funções. Revista Lusófona de Educação, v. 15, p. 191$194,2010$.

RODRIGUES, A. A matemática no ensino profissional. Os programas e as representações dos professores. 2015. Tese (Doutorado em Didátrica da Matemática) - Ciências, Universidade da Beira Interior, Covilhã, 2015.

RODRIGUES, A. Os programas de matemática no ensino profissional. In: ALMEIDA, A. J.; MATOS, J. M. (ed.). A matemática nos programas do ensino não-superior (1835-1974). Caparica: UIED/ APM, 2014. p. 95-113. 
RODRIGUEZ, M. V. Fontes e métodos: sua importância na descoberta das heranças educacionais. In: COSTA, C. L. J. et al. (eds.). Fontes e métodos em história da educação. Dourados: UFGD, 2010. p. 35-48.

SILVA, M. C. L. Processos de objetivação de saberes: o papel do expert e da expertise e os ensinos de geometria e desenho. Acta Scientiae, Canoas, v. 21, n. esp., p. 13-26, 2019. https://doi.org/10.17648/ acta.scientiae.v21 issEid5170

SOUSA, I. Manuais escolares de matemática para o Ciclo Preparatório do Ensino Técnico. 2012. Dissertação (Mestrado em Ensino de Matemática) - Faculdade de Ciências e Tecnologia, Universidade Nova de Lisboa, Lisboa, 2012.

VALENTE, W. R. História da educação matemática: interrogações metodológicas. REVEMAT Revista Eletrônica de Educação Matemática, Florianópolis, v. 2, n. 2, p. 28-42, 2007. https://doi. org/10.5007/\%25x

VASCONCELLOS, J. A reforma de Bellas-Artes. (Analyse do relatorio e projectos da commissão oficial nomeada em 10 de Novembro de 1875). Porto: Imp. Literário Comercial, 1877. 